\title{
Extracutaneous Melanoma: About Five Observations and Review of the Literature
}

\author{
Khadija Elboukhari ${ }^{1 *}$, Kaoutar Achehboune ${ }^{1}$, Sara Elloudi ${ }^{1}$, Hanane Baybay ${ }^{1}$, Nawal \\ Hammas $^{1}$, Leila Chbani ${ }^{2}$ and Fatima Zahra Mernissi ${ }^{1}$
}

${ }^{1}$ Department of Dermatology, University Hospital of Fez, Morocco

${ }^{2}$ Department of Anatomopathology, University Hospital of Fez, Morocco

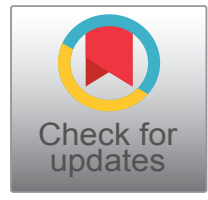

*Corresponding author: Khadija Elboukhari, Department of Dermatology, University Hospital of Fex, Morocco

\begin{abstract}
Extracutaneous melanoma is not a frequent situation, making a difficulty for the diagnosis. It is characterized by a poorer prognosis and rapid metastasis. The research for a primitive cutaneous melanoma is obligatory before retaining this entity. The dermatologist role is to eliminate a cutaneous primitive melanoma by the clinic and dermoscopic examination. We report five cases of non-cutaneous melanoma: Three mucosal melanoma, one choridian, and the fifth one is a parotid melanoma, and we will discuss this neoplasm via a literature review.
\end{abstract}

\section{Introduction}

Extracutaneous melanoma is a rare neoplastic affection, its epidemiology is sparsely described, and reported studies upon the literature are limited by time, and by geographic gaps in available data [1]. Its prevalence is about $4-5 \%$ only [2] with an annual age-adjusted incidence rate of 8.2 per million in the population [3] it's biologically knozed to be more aggressive than cutaneous melanoma [4]. The Clark level and Breslow are not available in this entity [4]. We report five cases of extracutaneous melanoma (choroidian, vaginal, anal and parotid).

\section{Methods}

Herein we describe five cases of non-cutaneous melanoma of different locations, with a literature review.

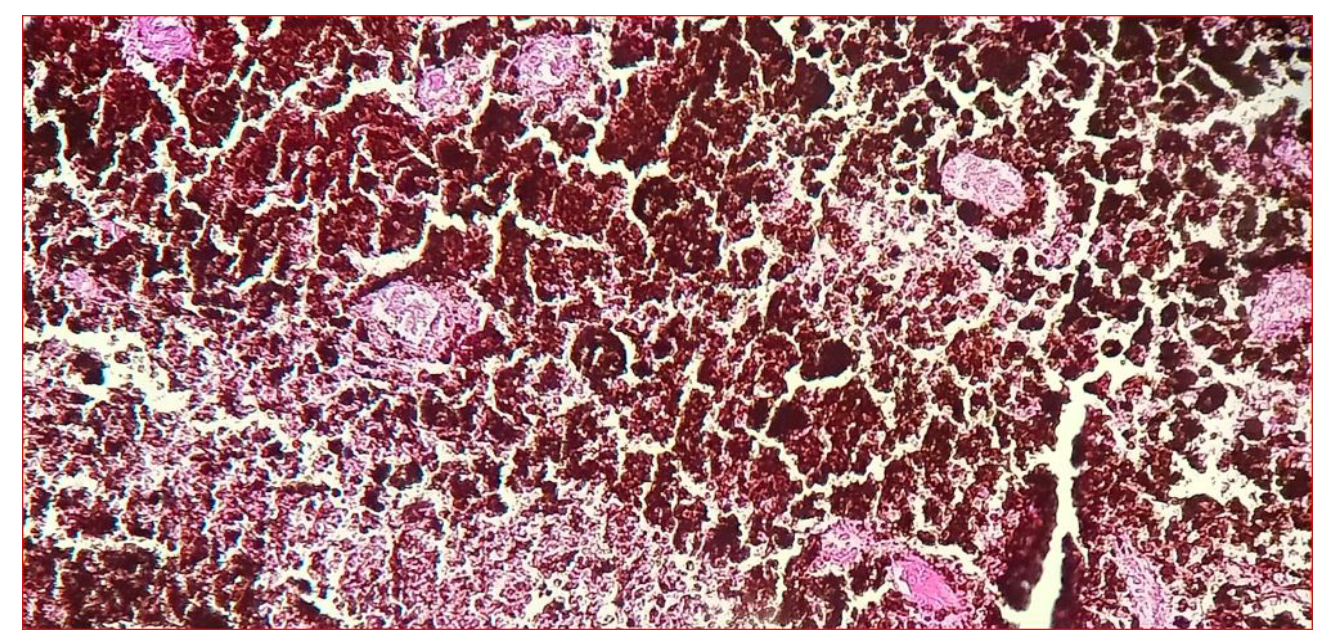

Figure 1: Gx200, epithelioid proliferation on the choroid with evident pigmentation.

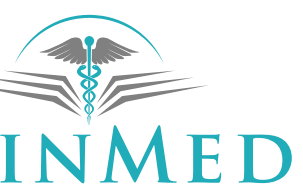

INTERNATIONAL LIBRARY

Citation: Elboukhari K, Achehboune K, Elloudi S, Baybay H, Hammas N, et al. (2020) Extracutaneous Melanoma: About Five Observations and Review of the Literature. Int J Cancer Clin Res 7:134. doi. org/10.23937/2378-3419/1410134

Accepted: April 14, 2020; Published: April 16, 2020

Copyright: (C) 2020 Elboukhari K, et al. This is an open-access article distributed under the terms of the Creative Commons Attribution License, which permits unrestricted use, distribution, and reproduction in any medium, provided the original author and source are credited. 


\section{Results}

\section{Case 1}

A 38-year-old patient with no pathological history, suffering from a progressive decrease in visual acuity without eye pain or oculomotor paralysis. Ophthalmologic examination revealed a pigmented retinal tumor indicating enucleation. Histopathological examination showed choroidal melanoma (Figure 1). The patient was referred to our structure and the dermatological examination did not detect any suspicious lesions. This patient did not need additional treatment with a threeyear follow-up without recurrence.

\section{Case 2}

A 41-year-old woman, had hematuria with the discovery of a pigmented polyploid tumor upon the ureteral meatus. Examination of the rest of the tegument did not objectify a suspicious skin lesion. After general anesthesia, surgical examination showed a pigmented

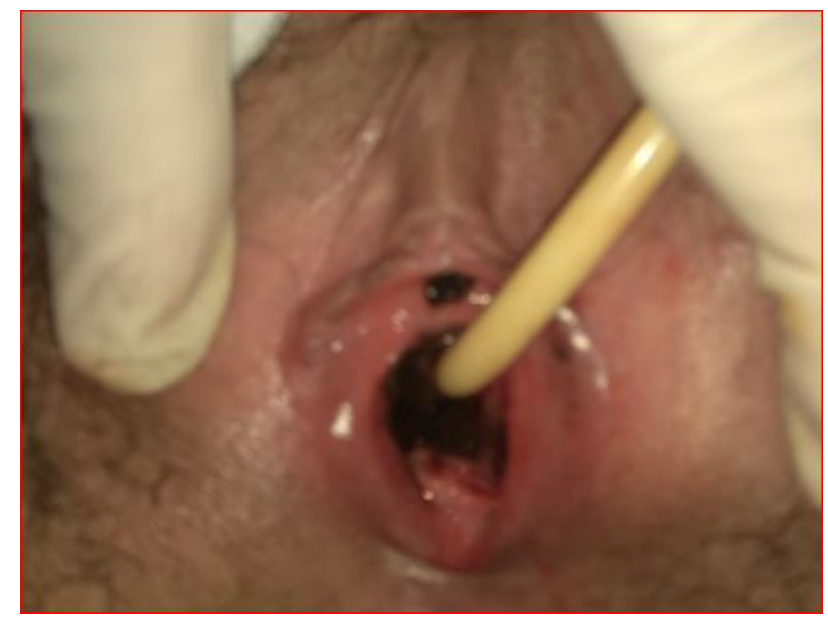

Figure 2: Black tumor arising in the uretheral meatus. periurethral swelling, tumor taking the meatus and the urethra with intravaginal extinction (Figure 2). A biopsy confirmed the diagnosis of Urethero-vaginal melanoma. The patient was judged not operable, and received chemotherapy after discovering lymphadenopathy and metastases in the assessment of extension. The treatment is still in progress.

\section{Case 3}

It's a 65-years-old man, who received an operation of the anal marge four years ago. The histologic examination was talking about an anal melanoma, the pa-

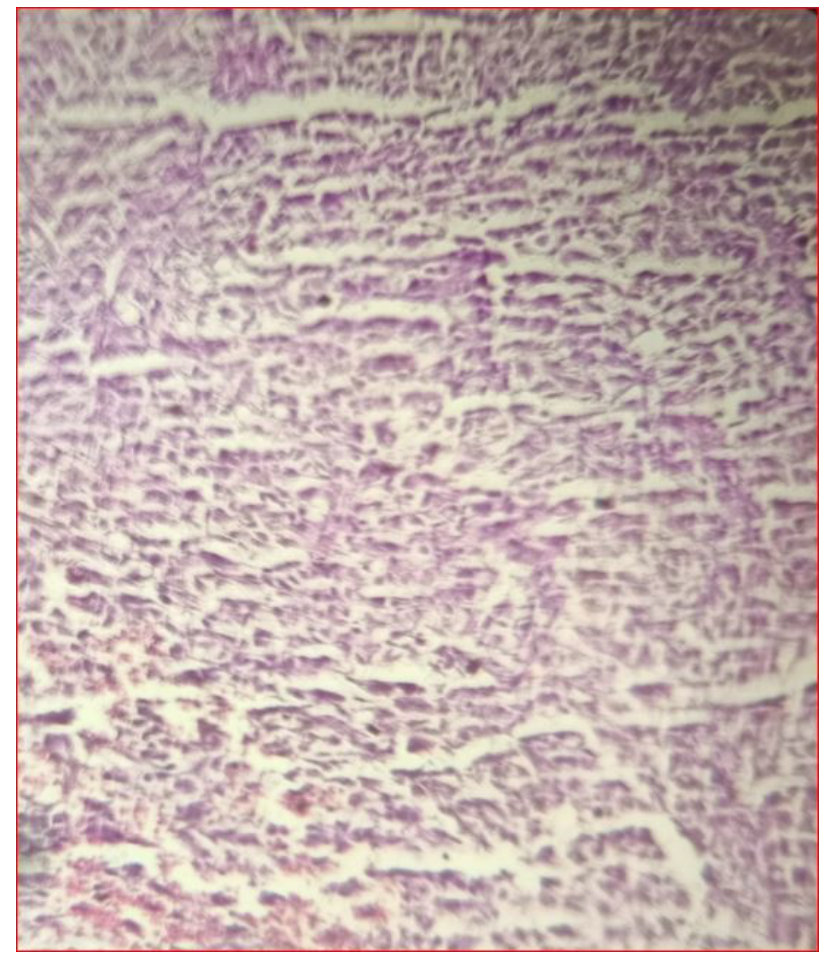

Figure 3: Gx400, epithelioid malignant proliferation on the rectum.

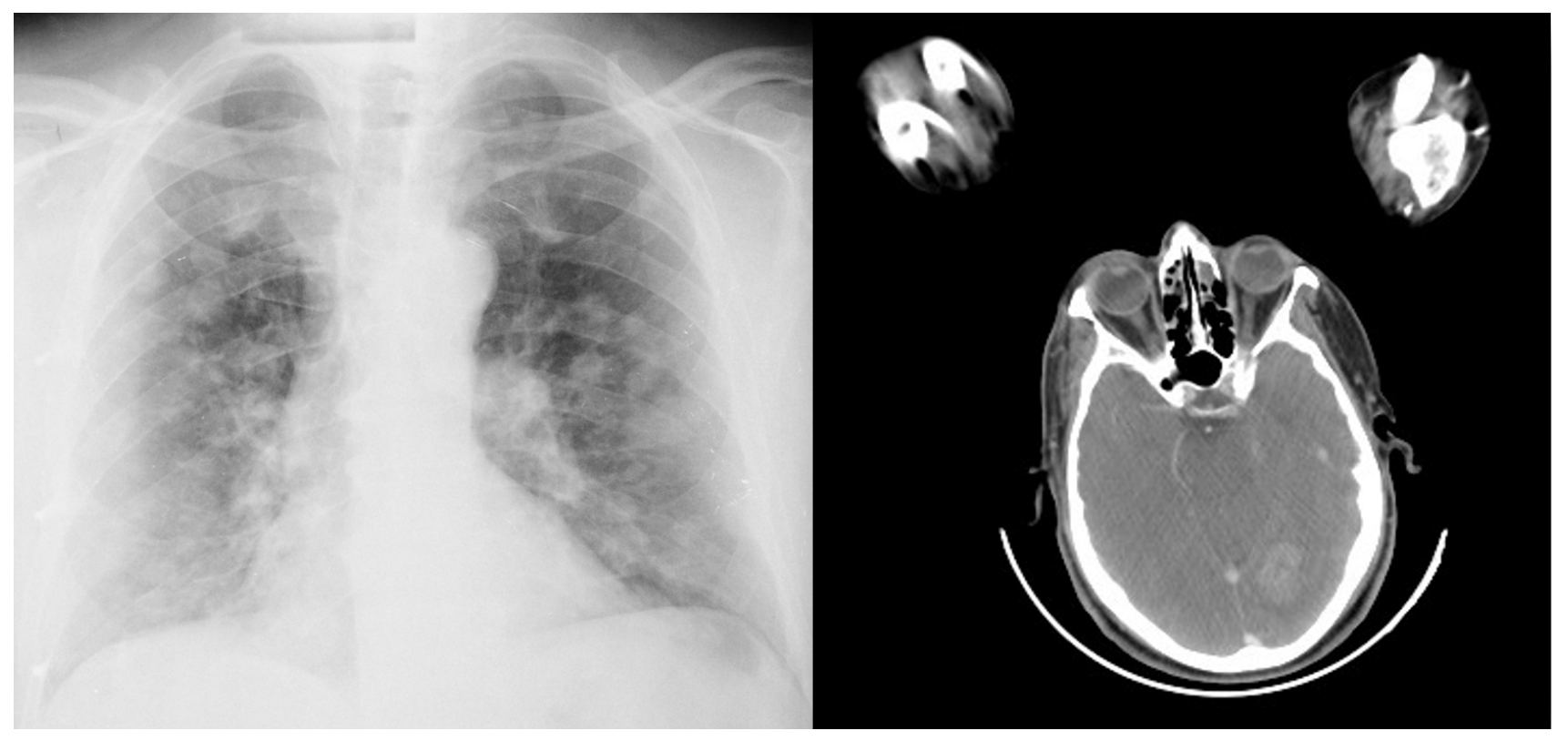

Figure 4: Pulmonary and cerebral metastasis of an anal melanoma. 
tient has been missed by a follow up, and came back to our structure after the apparition of an edema and a pigmented lesion of the left eyelid. Cutaneous metastasis of an anal melanoma has been retained and the scannographic imaging shoes diffuse metastasis, with cerebral, pulmonary locations (Figure 3). This patient died one month later without a specific cause.

\section{Case 4}

A patient of 71 years, having an antecedent of an explained nephrectomy of the right kidney 30 years ago suffered from an occlusive syndrome. After anorectal examination, a process of the rectum have been observed, the histological analysis found a melanoma of the rectum (Figure 4), and the patient benefited of an abdominopelvis amputation with definitive stomy. The extensif imaging showed hepatic and splenic secondary locations, the patient received adjuvant radiotherapy and chemotherapy after multidisciplinary decision. The patient was referred to our structure, and we did not found any suspicious lesion on clinic and dermoscopic examination.

\section{Case 5}

A 56-year-old woman, with a history of cerebral ischemic stroke four years ago. Presented for the past two years a palpable nodule in the left mandibular region, gradually increasing in size. Initial scannographic exploration showed an intraparotidian tissue process of $9 \times$ $5 \mathrm{~cm}$ long axis projecting into the adjacent soft tissues with infiltration of the sternocleidomastoid muscle, The biopsy discovered a melanoma with positive immunohistochemistry (melan A HMB 45PS 100 and SOX-10) In addition, the patient had no cutaneous or mucosal lesions suggestive of malignancy. In the extension assessment, the patient benefited from a cerebro-thoraco abdominopelvic tomodensitometry showing secondary locations. Then the patient received radiotherapy with palliative chemotherapy (Table 1).

\section{Discussion}

Generally, Melanoma is categorized on cutaneous, mucosal and ocular according to McLaulin, et al. In other words, extracutaneous melanoma included ocular, anorectal, mucosal, nail beds, conjunctival, vaginal, urogenital, orbital, esophageal, and leptomeningeal malig- nant melanomas [3].

There are such criteria defined by Ainsworth and colleagues and Carstens and colleagues respectively in 1976 and 1984 [5] to retain a non-cutaneous primitive melanoma.

\section{Mucosal melanoma}

Mucosal melanoma is a rare variety, representing only $1.4 \%$ of all melanomas [3]. This aggressive tumor occurs in elderly patients [3], the average age is 70 versus 44 for cutaneous melanoma [6]. Out of the buccal melanoma, the most frequent mucosal melanoma are respectively urogenital and anorectal mucosal melanoma.

\section{Urogenital melanoma}

Genitourinary and precisely the vulvovaginal location are the most frequent mucosal melanoma, that explain its frequencies on female versus male [7], with a sex ratio of 0.54 [3], compared to the cutaneous melanoma, the Multifocal and amelanotic character is more frequent in this entity [8]. It's quite rare and consisting on less than $3 \%$ of malignant vaginal tumors [9] manifesting by a pigmented macula with irregular borders associated to pruritus or bleeding. Imaging findings shows an infiltrating parietal mass with isotohyperintense signal on T1-weighted MRI and usually hyperintensesignal on T2-weighted images [6]. Rapid spreading and fatal evolution are habitual, and resection is generally difficult. Either tumoral resection has been successful, the prognosis is almost poor, with a median survival of 12-25 months, both of our patients having this location have a poor prognosis which concords of the literature data [10-12]. The mainstay therapy is the surgical excision, if the tumor spreads to the bladder or rectum, an anterior or posterior extenteration [4], the hysterectomy is indicated if the tumor is in the upper vaginal third part [13].

\section{Anorectal mucosal melanoma}

It represents a few parts of the colorectal malignancies, 0.05 percent of all tumors of this area [14]. It has been proved that HIV infection increases the risk of anorectal melanoma [15]. Rectal location is the most reported (42\%), followed by the anal canal (33\%) [14]. It's is usually seen as an intraluminal fungating or polypoid

Table 1: Clinical characteristics of our case series of non-cutaneous melanoma.

\begin{tabular}{|l|l|l|l|l|l|l|}
\hline & Age & Sex & Onset date & Principal symptom & $\begin{array}{l}\text { Primitive location } \\
\text { of the melanoma }\end{array}$ & treatment \\
\hline Case 1 & 38 & F & One year & Decrease in visual acuity & Choroid & Orbital exenteration \\
\hline Case 2 & 41 & F & imprecise & Hematuria & Urethre & Palliative radiochemotherapy \\
\hline Case 3 & 65 & M & imprecise & $\begin{array}{l}\text { Unprecise (retrospective } \\
\text { diagnosis) }\end{array}$ & Anal & Anal resection \\
\hline Case 4 & 71 & M & imprecise & Subocclusif syndroma & Anorectal & Abdominopeliv exentheration \\
\hline Case 5 & 56 & F & Two year & $\begin{array}{l}\text { Painful achromic tumor of } \\
\text { the parotid }\end{array}$ & Parotid & $\begin{array}{l}\text { Radiotherpay and palliative } \\
\text { chemotherapy }\end{array}$ \\
\hline
\end{tabular}




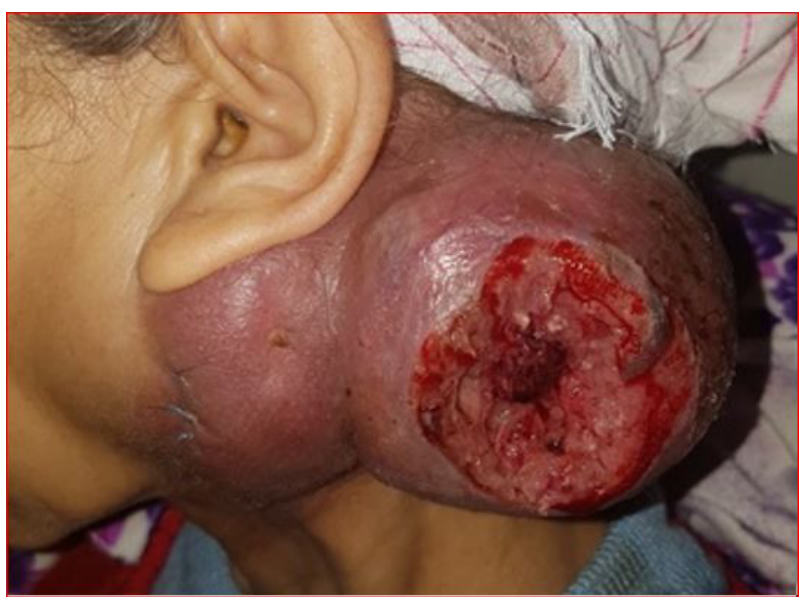

Figure 5: Melanoma of the parotid: Bilobed ulcerated amelanotic tumor.

mass in the anal canal or the distal part of rectum with Perirectal infiltration [6]. Abdominoperineal resection is the recommended treatment, with a considerable comorbidity $[13,16]$. That was the case of our patient. In additional, lymph node resection has not been recommended because there is no effective amelioration of the median survival with such radical surgery [16-18]. As like as all metastatic melanoma, a systemic chemotherapy or immunotherapy is recommended (Dacarbazin, Mimustine, Vincristine and Interferon beta).

\section{Ocular melanoma}

Ocular melanoma is a Uveal melanoma in $80 \%$ of the cases [3]. It is the most common ocular tumor, including iris, ciliary body and choroid. Its incidence is about 5.1 per million habitant annually.

It affects white race people $97.8 \%$ versus $0.8 \%$ of black race people [19], and may be associated with ota naevus [20]. This affection is first detected by the ophtalmologists, then ultrasonography can be a useful imaging but not sufficient, MRI is necessary for the exact delineation of the tumor and evaluation of optic nerve involvement and extraocular extension [6]. Clinical and histological manifestation of uveal melanoma is variable, making so difficult to clinically differentiate it from other neuroectodermal tumors with melanin content such as melanocytoma, melanotic meningioma, schwannoma and neurofibroma [21-23].

Radiation is the mainstay therapy, but large and unsuitably located melanoma of the choroid must be treated by enucleation and that was the case of our patient. Radiosurgery with the gamma knife may be benefic with $98 \%$ of local control during the three first years during the follow up [24].

\section{Melanoma in the parotid gland}

Parotid melanoma with unknown primary is recognized in the literature but still be incompletely described. There is a study published by Scott, et al. in 2016 concluding that patients having a primary mel- anoma of the parotid with unknown primitive tumor have a poorer prognosis compared to parotid melanoma with known primary tumor [25]. In this study, there was a lack to differentiate between a primary melanoma of the parotid and a parotidian melanoma with an unknown primitive tumor. Several studies are needed to clarify this confusion and define this entity of primary parotid melanoma (Figure 5).

Finally, other localizations are well described in the literature. Among them, we cite the primary melanoma of the lung, which represent $0.01 \%$ of all lung tumors [26], melanoma of the tractus digest if whose incidence is increasing [15]. An anecdotal reported location is the retroperitoine, where the diagnostic of primary melanoma was a challenge [5].

\section{Conclusion}

Extracutaneous melanoma is a well-defined entity. Its pathogenesis remain unclear with more aggressively and high risk of metastasis. Dermatological examination is indispensable to retain the diagnosis by eliminating a cutaneous primitive melanoma. The Management of this pathology requires a multidisciplinary collaboration with a closed follow up.

\section{Competing Interests}

The authors declare no competing interest.

\section{Authors' Contributions}

All the authors contributed to the conduct of this work. All authors also state that they have read and approved the final version of the manuscript.

\section{Acknowledgements}

We are indebted to our patients for giving us the consent for the publication.

\section{References}

1. Haiducu ML, Hinek A, Astanehe A, Lee TK, Kalia S (2014) Extracutaneous melanoma epidemiology in British Columbia. Melanoma Research 24: 377-380.

2. Hussein MR (2008) Extracutaneous Malignant Melanomas. Cancer Investigation 26: 516-534.

3. McLaughlin CC, Wu XC, Jemal A, Martin HJ, Roche LM, et al. (2005) Incidence of non-cutaneous melanomas in the U.S. Cancer 103: 1000-1007

4. Thoelke A, Willrodt S, Hauschild A, Schadendorf D (2004) Primary Extracutaneous Malignant Melanoma: A Comprehensive Review with Emphasis on Treatment. Oncology Research and Treatment 27: 492-499.

5. Alsharedi M, Zgheib NB, Khelfa $Y$, Raufi A, Elmsherghi N, et al. (2016) Primary Retroperitoneal Melanoma Presented in a Rare Extracutaneous Site for Malignant Melanoma. Rare Tumors 8: 134-136.

6. Keraliya AR, Krajewski KM, Braschi-Amirfarzan M, Tirumani SH, Shinagare AB, et al. (2015) Extracutaneous melanomas: A primer for the radiologist. Insights into Imaging 6: 707-717. 
7. Altieri L, Wong MK, Peng DH, Cockburn M (2017) Mucosal melanomas in the racially diverse population of California. Journal of the American Academy of Dermatology 76: 250257.

8. Carvajal RD, Spencer SA, Lydiatt W (2012) Mucosal Melanoma: A Clinically and Biologically Unique Disease Entity. J Natl Compr Canc Netw 10: 345-356.

9. Chaudhuri S, Das D, Chowdhury S, Gupta AD (2013) Primary malignant melanoma of the vagina: A case report and review of literature. South Asian Journal of Cancer 2: 4.

10. Dominiak NR, Wick MR, Smith MT (2016) Mucosal melanomas: Site-specific information, comparisons with cutaneous tumors, and differential diagnosis. Seminars in Diagnostic Pathology 33: 191-197.

11. Ellis ZM, Jassim AD, Wick MR (2010) Anorectal melanoma in childhood and adolescence. Annals of Diagnostic Pathology 14: 69-73.

12. Chute DJ, Cousar JB, Mills SE (2006) Anorectal Malignant Melanoma: Morphologic and Immunohistochemical Features. Am J Clin Pathol 126: 93-100.

13. Ariel IM (1981) Malignant melanoma of the female genital system: A report of 48 patients and review of the literature. J Surg Oncol 16: 371-383.

14. Cagir B, Whiteford MH, Topham A, Rakinic J, Fry RD (1999) Changing epidemiology of anorectal melanoma: Diseases of the Colon and Rectum 42: 1203-1208.

15. Coté TR, Sobin LH (2009) Primary melanomas of the esophagus and anorectum: Epidemiologic comparison with melanoma of the skin. Melanoma Research 19: 58-60.

16. Ooi BS, Eu KW, Seow-Choen F (2001) Primary anorectal malignant melanoma: Clinical features and results of surgical therapy in Singapore--a case series. Ann Acad Med Singap 30: 203-205.
17. Ross M, Pezzi C, Pezzi T, Meurer D, Hickey R, et al. (1990) Patterns of Failure in Anorectal Melanoma: A Guide to Surgical Therapy. Arch Surg 125: 313.

18. Meng Su, Lucheng Zhu, Wenhua Luo, Hangping Wei, Changlin Zou (2014) Primary anorectal malignant melanoma treated with neoadjuvant chemoradiotherapy and sphincter-sparing surgery: A case report. Oncol Lett 7: 1605-1607.

19. Diwo E, Merle H (2013) Mélanome du corps ciliaire révélé par une uvéite chez un sujet mélanoderme, à propos d'un cas et revue de la littérature. Journal Français d'Ophtalmologie 36: e191-e195.

20. Radhadevi CV, Charles KS, Lathika VK (2013) Orbital malignant melanoma associated with nevus of Ota. Indian $\mathrm{J}$ Ophthalmol 61: 306-309.

21. Haytham E Nasr, Mohamed A Nouh, Rania A Ahmed, Abdelrahman M Elhusseiny (2018) Orbital melanocytoma: When a tumor becomes a relieving surprise. American Journal of Ophthalmology Case Reports 10: 124-127.

22. Brat DJ, Giannini C, Scheithauer BW, Burger PC (1999) Primary melanocytic neoplasms of the central nervous systems. Am J Surg Pathol 23: 745-754.

23. Mathai AM, Naik R, Pai MR, Kini JR, Kumar S, et al. (2008) Orbital Melanocytoma. Orbit 27: 383-387.

24. Mueller AJ, Talies S, Schaller UC, Horstmann G, Wowra B, et al. (2000) Stereotactic radiosurgery of large uveal melanomas with the gamma-knife. Ophthalmology 107: 1381-1387.

25. Jeffrey F Scott, Cheryl L Thompson, Ritva Vyas, Kord Honda, Chad Zender, et al. (2016) Parotid melanoma of unknown primary. Journal of Cancer Research and Clinical Oncology 142: 1529-1537.

26. Liu GH, Liu J, Dong H, Tang XJ (2014) Primary malignant melanoma of the lung: a case report. Int $\mathrm{J}$ Clin Exp Med 7: $1757-1759$ 